\title{
Modeling and Simulation of the Influence of Intermittent Distributed Generators on Distribution System Transients
}

\author{
Ke-yan LIU ${ }^{1}$ \& Dong-li JIA \\ Qian-yu ZHAO 2 \\ ${ }^{1}$ Beijing Key Laboratory of Distribution Transformer Energy-saving Technology, China Electric \\ Power Research Institute, Haidian District, Beijing 100192, China \\ ${ }^{2}$ Key Laboratory of Smart Grid of Ministry of Education, Tianjin University, Tianjin 300072, China
}

KEYWORD: Distribution system, distributed generator, illumination intensity, temperature, wind speed, high permeability

ABSTRACT: The transient models of wind power generation system and photovoltaic (PV) power generation system are established. The constant power control mode is used to control the photovoltaic system and wind system, which is achieved by controlling DC voltage. And a direct drive permanent magnet synchronous generator of variable speed constant frequency is adopted for wind power generator. The PSCAD simulation tool is used to establish electromagnetic transient model of distribution system, and the influence of the changes of illumination intensity, temperature, wind speed and different permeability of intermittent distributed generators (DGs) on distribution system transients is discussed through the PSCAD simulation. The result shows that the influence of intermittent DGs on distribution system transients is significant when the system is with high penetration of DGs.

\section{INTRODUCTION}

Intermittent DG supplying to network is a new challenge to the safe operation of distribution system which can relieve the pressure of environmental pollution and energy shortage. The future distribution system must be able to accept different types of DG and can make reasonable scheduling and control. DG is a power generation facility that is directly installed in the distribution system or in the vicinity of the load, which can generate electricity efficiently, reliably and steadily. At present, the proportion of PV and wind turbine is growing. The intermittent distributed energy need to cooperate with energy storage device to supply in the island operation while in the grid connected operation, the intermittent distributed energy can be access to the distribution system independently. The accessing of a large amount of DGs result in the difference between the power flow, voltage and relay protection and the traditional single power distribution network system. Therefore, it is necessary to analyze the transient of the distributed power supplying to the distribution network.

The PV power transmission mutation and short fault transient operating characteristics was analyzed based on the transient models for grid connected PV power generation system of voltage source converter in literature 1. Literature [2,3] adopted eigenvalues method to analysis the dynamic stability characteristics of the grid connected PV power generation system, which is a method of direct calculation of stability, but not using time domain simulation. The effect on the transient stability of scattered hydropower stations and wind farms accessing to the distribution network is studied in the paper [4].Above literatures all study the effect of only PV power generation or only wind power on the distribution network but not research the common influence on the distribution system.

Firstly the PV power system and wind power system transient characteristics and control strategy is studied and the transient models of the PV system and wind power system are established in PSCAD. Then the impact of the illumination intensity, temperature, wind speed changes and different permeability of intermittent DGs on distribution system transients is discussed through the simulation with the electromagnetic transient model of the distribution system. 


\section{STRUCTURE OF THE SYSTEM}

The system is shown in Fig.1 including the transient models of PV power generation system, wind power generation system and five nodes distribution network.

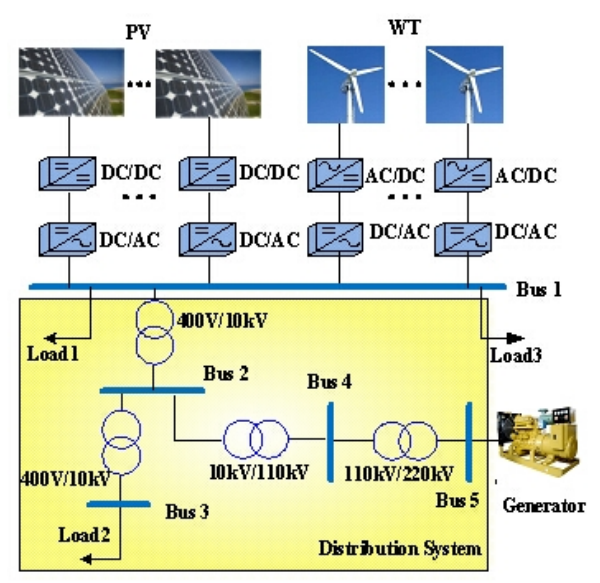

Fig.1 The structure of intermittent DGs supplying to the distribution network

\section{Transient Model of PV Power Generation System}

The component of PV power generation system includes $\mathrm{PV}$ arrays, DC/DC inverter and DC/AC converter. The modeling of DC/DC is mainly MPPT control and the modeling of DC/AC is mainly $\mathrm{DC}$ bus voltage and power control, the structure diagram is shown in Figure 2. By controlling the duty cycle of the DC/DC circuit to achieve the maximum power tracking and the perturbation method is used. Converter control is mainly used to adjust the grid current to be same-phase with the grid and has a low harmonic distortion which can improve power quality. Double loop control strategy for grid connected inverter is adopted which the outer loop is a DC voltage control and reactive power control and the inner loop is current control. DC voltage control is to ensure the constant voltage on the DC side of the inverter that makes the flow through the DC capacitance current small, so as to ensure the inverter be capable of a maximum transmission of PV array power. The PV power generation system mainly adopts the constant power control mode and the active power is realized through controlling the DC voltage in the grid connected mode.

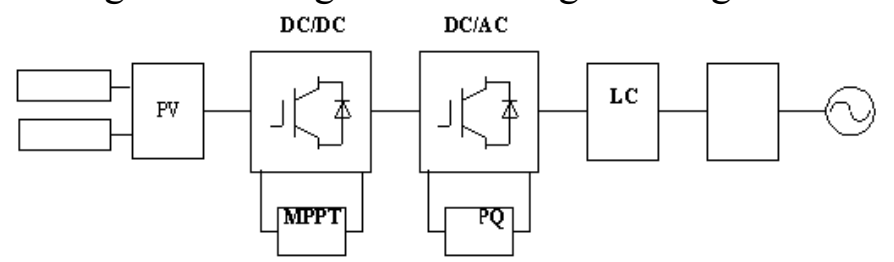

Fig. 2 grid connected system structure diagram of PV power generation system

\section{PV array and DC bus model}

Assuming that the PV array is $\mathrm{n} \times \mathrm{m}$ and the $\mathrm{V}$-I characteristic of the PV array is:

$$
I=m I_{\mathrm{ph}}-m I_{\mathrm{d}}\left[e^{\frac{q\left(V / n+I R_{\mathrm{s}} / m\right)}{A k T}}-1\right]-m \frac{V / n+I R_{\mathrm{s}} / m}{R_{\mathrm{sh}}}
$$

The $R_{\mathrm{s}}$ and $I_{\mathrm{ph}}$ are equivalent series impedance and shunt impedance respectively. The $R_{\mathrm{sh}}$ is expressed as the photo current, $T$ is the battery temperature, and $I_{\mathrm{d}}$ is the reverse saturable leakage current flowing through the diode.

$I_{\mathrm{ph}}$ and $I_{\mathrm{d}}$ can be calculated by formula (2) and formula (3).

$$
\begin{gathered}
I_{\mathrm{ph}}=I_{\mathrm{sco}} \cdot\left[1+h_{1} \cdot\left(T-T_{\mathrm{o}}\right)\right] \cdot \frac{\phi}{\phi_{\mathrm{o}}} \\
I_{\mathrm{d}}=b \cdot T^{3} \cdot \exp (-a / T)
\end{gathered}
$$


In the Formula (2), (3), $I_{\text {sco }}$ is short circuit of current insolation Standard and standard temperature; $\mathrm{h} 1$ is temperature coefficient and $T_{\mathrm{o}}$ is absolute reference tempera-

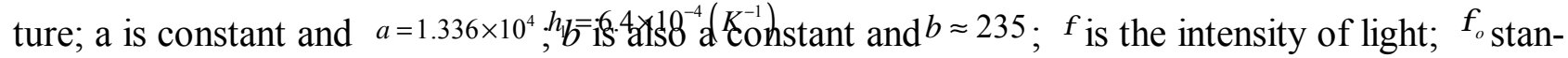
dard light intensity.

\section{DC/DC control model}

The MPPT algorithm is a variable step size of the perturbation method in this paper. Power increment $d \mathrm{P}$ and voltage increment $d \mathrm{~V}$ has the following characteristics by the $\mathrm{P}-\mathrm{V}$ curve of $\mathrm{PV}$ cells.

At the left side of the maximum power point: $d P / d V>0$; at the right side: $d P / d V<0$; the maximum power point is: $\mathrm{dP} / \mathrm{dV}=0$. And the absolute value is smaller when the absolute value of the operating point is near the maximum power point, so the step size can be $\alpha|\mathrm{d} P / \mathrm{d} V|$ ( $\alpha$ is the coefficient).

Select large disturbance when the power point of the PV power supply is far from the maximum power point and choose small perturbation when the operating point near the maximum power point. This paper adopts the improved variable step perturbation and observation method with flow chart as shown in figure. 3 .

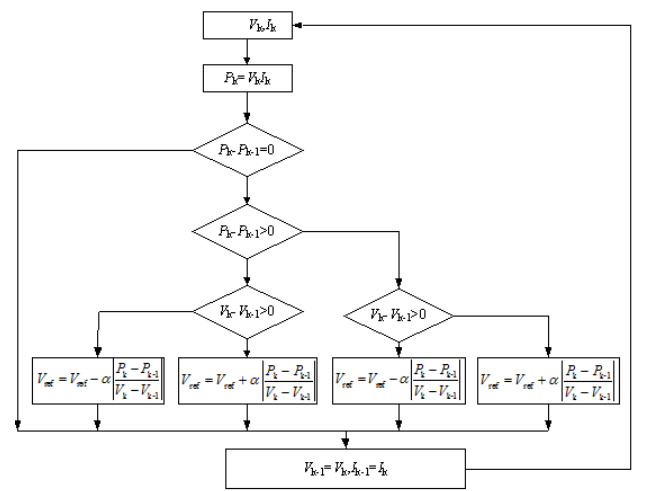

Fig.3 the flow chart of perturbation concept algorithm of variable step size

\section{Inverter DC/AC control model}

Grid connected control model of PV power generation system is shown in Figure 4. The input active power and reactive power of PV power generation system are controlled by changing the reference value of active power and reactive power.

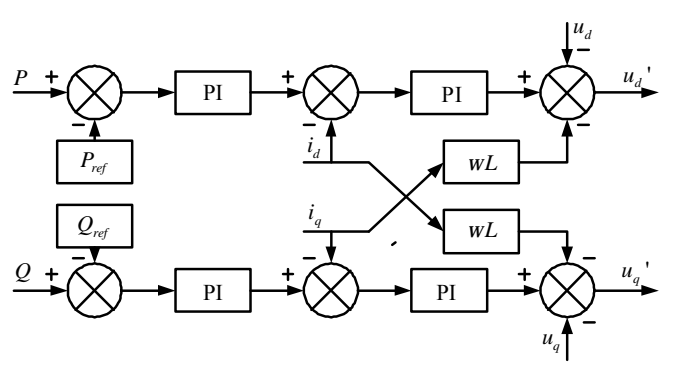

Figure 4 inverter control model

\section{Transient model of wind power generation system}

Permanent magnet synchronous direct drive wind power generation system belongs to the variable speed constant frequency wind power generation system including air power system model, permanent magnet synchronous generator and converter control, and the system structure diagram as shown in Figure 5. In grid connection, the wind power generation system mainly adopts the constant power control mode, and the active power is realized by controlling the DC voltage. 


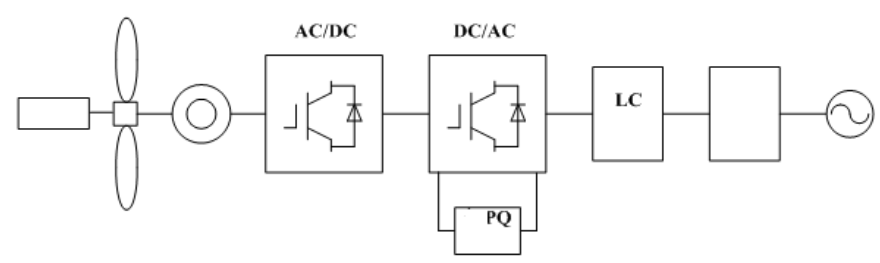

Figure 5 grid connected system structure diagram of wind power generation system

\section{The wind wheel model}

The input of the wind wheel model is $v_{\mathrm{w}}$ and $\omega_{\mathrm{w}}$, and the output is $T_{\mathrm{m}}$. The relationship between $v_{\mathrm{w}}$ and $P_{\mathrm{w}}\left(P_{\mathrm{w}}\right.$ is mechanical power which is the wind turbine's acquisition of wind energy $)$ is:

$$
P_{\mathrm{w}}=\frac{1}{2} \rho c_{\mathrm{p}}(\lambda, \beta) A_{\mathrm{r}} v^{3}{ }_{\mathrm{w}}
$$

As shown in the formula: $\rho$ is air density; $c_{\mathrm{p}}$ is wind energy conversion efficiency coefficient, is the function of tip speed ratio $\lambda\left(\lambda=\omega_{\mathrm{w}} R / \nu_{\mathrm{w}}\right)$ and pitch angle $\beta, \mathrm{R}$ is the radius of the wind wheel; $A_{\mathrm{r}}$ is the blade sweep grazing area.

The mechanical torque of the low speed shaft of the transmission chain is:

\section{Transmission chain model}

$$
T_{\mathrm{m}}=\frac{P_{\mathrm{w}}}{\omega_{\mathrm{w}}}
$$

The function of transmission chain is that the mechanical energy of the wind turbine can be transferred to the generator. The transmission chain model inputs are $T_{\mathrm{m}}$ and $T_{\mathrm{e}}$, the outputs are $\omega_{\mathrm{w}}$ and $\omega_{\mathrm{g}}$.

$$
\left\{\begin{array}{l}
2 H_{\mathrm{m}} D \omega_{\mathrm{w}}=T_{\mathrm{m}}-K_{\mathrm{s}} \theta_{\mathrm{s}}-D_{\mathrm{m}} \omega_{\mathrm{w}} \\
2 H_{\mathrm{m}} D \omega_{\mathrm{g}}=K_{\mathrm{s}} \theta_{\mathrm{s}}-T_{\mathrm{e}}-D_{\mathrm{g}} \omega_{\mathrm{g}} \\
D \theta_{\mathrm{s}}=\omega_{\mathrm{s}}\left(\omega_{\mathrm{w}}-\omega_{\mathrm{g}}\right)
\end{array}\right.
$$

As shown in the formula: $\mathrm{D}$ is a differential operator; $H_{\mathrm{m}}$ and $D_{\mathrm{m}}$ are inertia time constant and damping coefficient of wind wheel, low-speed shaft and gear box overall respectively; $H_{\mathrm{g}}$ and $D_{\mathrm{g}}$ areinertia time constant and damping coefficient of generator rotor respectively; $K_{\mathrm{s}}$ is rigidity coefficient of equivalent high speed shaft; $\theta_{\mathrm{s}}$ is torsional angle of a high speed shaft, $\omega_{\mathrm{s}}$ is synchronous speed.

The transmission chain of wind power generation system can be further reduced to 1 degree model, which is considered as a rigid body. At this time

$$
\left\{\begin{array}{l}
\omega_{\mathrm{w}}=\omega_{\mathrm{g}} \\
\theta_{\mathrm{g}}=0 \\
K_{\mathrm{s}}=\infty
\end{array}\right.
$$

Put the formula (7) into the equation (6) can get 1 order model of transmission chain:

$$
2 H_{\mathrm{L}} D \omega_{\mathrm{L}}=T_{\mathrm{m}}-T_{\mathrm{e}}-D_{\mathrm{L}} \omega_{\mathrm{L}}
$$

As shown in the formula: $H_{\mathrm{L}}$ is the inertia time constant of the transmission chain, $H_{\mathrm{L}}=H_{\mathrm{m}}+H_{\mathrm{g}} . \omega_{\mathrm{L}}$ is the angular velocity of the transmission chain, $\omega_{\mathrm{L}}=\omega_{\mathrm{w}}=\omega_{\mathrm{g}} . D_{\mathrm{L}}$ is amping coefficient of the transmission chain, $D_{\mathrm{L}}=D_{\mathrm{m}}+D_{\mathrm{g}}$.

\section{generator model}

2 stage electromagnetic transient model for permanent magnet synchronous generator is as follows:

$$
\boldsymbol{u}_{\mathrm{s}}=-r_{\mathrm{s}} i_{\mathrm{s}}+D \psi_{\mathrm{s}}+j \omega_{\mathrm{s}} \psi_{\mathrm{s}} \quad \boldsymbol{\psi}_{\mathrm{s}}=-L_{\mathrm{s}} i_{\mathrm{s}}+\psi_{\mathrm{p}}
$$

As shown in the formula: $\boldsymbol{\Psi}_{\mathrm{p}}=\left[\begin{array}{ll}\psi_{\mathrm{pd}} & 0\end{array}\right]^{\mathrm{T}}$ is permanent magnet flux linkage vector. $\psi_{\mathrm{pd}}$ in $\boldsymbol{\Psi}_{\mathrm{p}}$ is d-axis secondary beam generated by permanent magnet. $\boldsymbol{u}$ is voltage vector. $\boldsymbol{i}$ is current vector. $\boldsymbol{\Psi}$ is flux linkage vector. $r$ is the resistance. $L$ is the inductance. subscript $\mathrm{s}$ expressed stator side.

\section{Converter control model}

In wind power generation system, PWM converter usually used double closed loop control, as shown in Figure 6 which $X$ and $X_{\text {Ref }}$ indicated the control variables and the reference value respectively, which can be active power $P$, reactive power $Q$, electromagnetic torque $T_{\mathrm{e}}$, system frequency 
$f$, bus voltage $U_{\mathrm{s}}$ or DC voltage $U_{\mathrm{dc}} . K_{1}, T_{1}, K_{2}, T_{2}$ are the controller parameters. Subscript min, Max, ref expressed the minimum value, the maximum value and the reference value respectively.

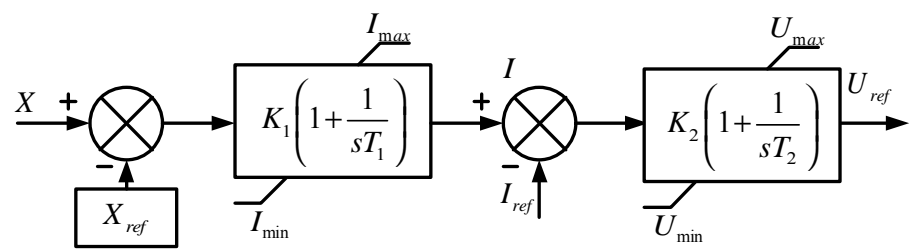

Figure 6 PWM converter control model

\section{IMPACT ON TRANSIENT OF DISTRIBUTION NETWORK}

\section{When the Temperature Changes}

Reference battery temperature $T_{\text {ref }}$ is equal to $298 \mathrm{~K}$. The temperature in the $t=3 \mathrm{~s}$ changes from $400 \mathrm{~K}$ to $350 \mathrm{~K}$ and in the $t=4 \mathrm{~s}$ changes from $350 \mathrm{~K}$ to $300 \mathrm{~K}$ when sunshine intensity unchanged which named $S=1100 \mathrm{~W} / \mathrm{m}^{2}$, PV panel output voltage, current and power change as shown in Figure 7 . Fig. 7 shows that current in the temperature changes have been volatile and power output is stable at the MPPT.

When the temperature fluctuated the DC bus voltage has a small shock but soon recovery to the constant value so as to remain the voltage constant by control the DC bus voltage constant which as shown in Figure 8. Corresponding output current of the PV power generation system is changed as shown in Figure 9. The transient process of the current is relatively short and has a small range of fluctuations. Distribution network bus 4 power changes as shown in Figure 10, the power of the bus changes with the change of the PV output and has a small range of fluctuations, but the overall trend is stable.

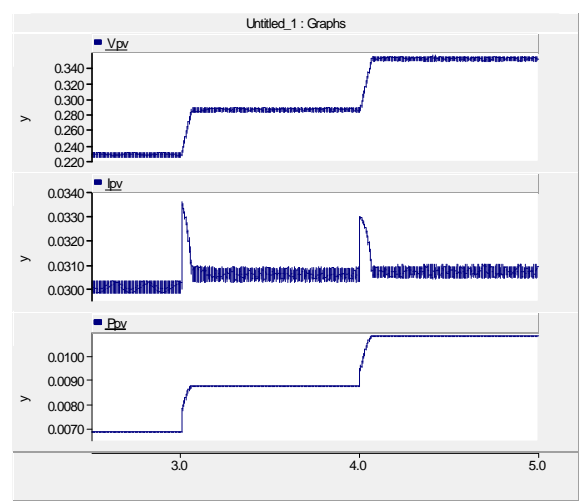

Fig. 7 output voltage, current and power change of PV array

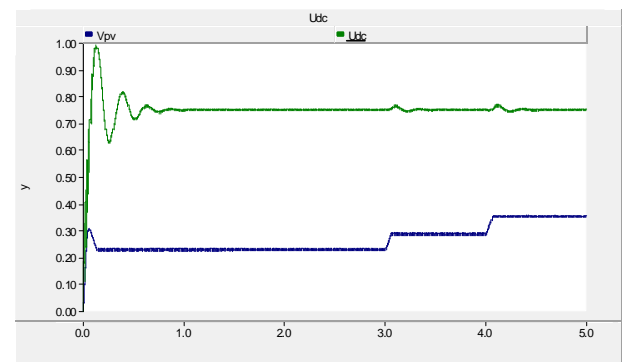

Fig. 8bus voltage Udc change of PV 


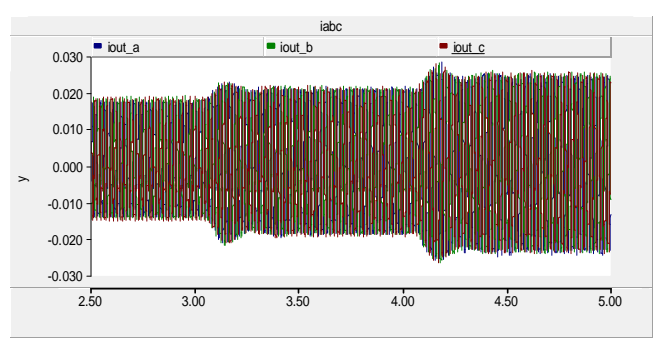

Fig. 9 output current change of PV

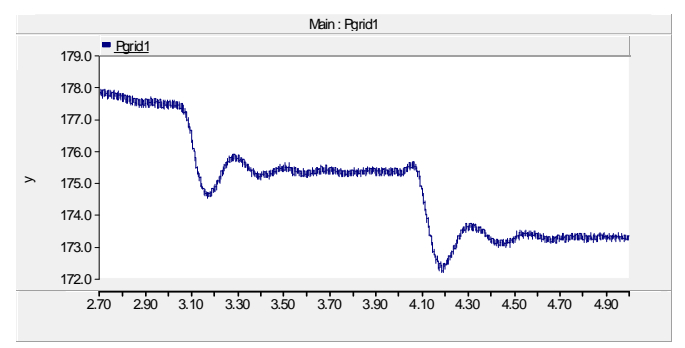

Fig. 10 power change of distribution network bus 1

\section{When the Sunshine Intensity of PV Changes}

Reference light illumination intensity $S_{\text {ref }}$ is equal to $1000 \mathrm{~W} / \mathrm{m}^{2}$. The intensity of sunlight in the $\mathrm{t}=3 \mathrm{~s}$ increases from $200 \mathrm{~W} / \mathrm{m}^{2}$ to $500 \mathrm{~W} / \mathrm{m}^{2}$ and $\mathrm{t}=4 \mathrm{~s}$ changes to $1000 \mathrm{~W} / \mathrm{m}^{2} 2$ while the temperature $\mathrm{T}=$ $300 \mathrm{~K}$ remain unchanged, PV panel output voltage and current and power change situation as shown in Figure 11.By Figure 11 shows, voltage in sunlight intensity changes have been volatile, power output remain stable at the MPPT which is different with temperature changes. DC bus voltage $U_{\mathrm{dc}}$ changes as shown in Figure 12 adopted the DC bus voltage control and the DC bus voltage has a small shock, but soon recovery value and the DC bus voltage is kept constantwhen temperature fluctuations. Corresponding output current of the PV power generation system is changed as shown in Figure 13. The transient process of the current is longer than that of the temperature. Distribution network bus 4 power changes as shown in Figure 14, the power of the bus changes with the change of the PV output and has a small range of fluctuations, but the overall trend is stable.

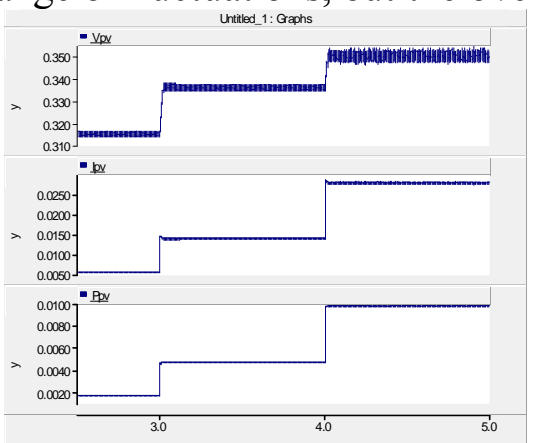

Fig. 11 output voltage, current and power change of PV array

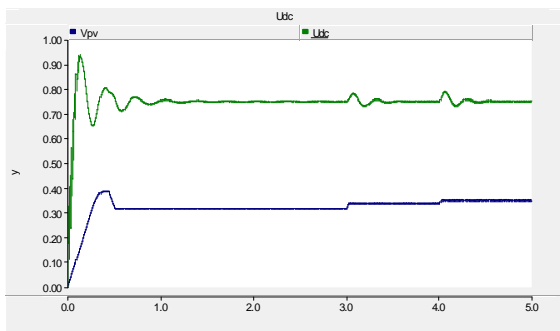

Fig. 12 output voltage Vpv and bus voltage Udc change of PV 


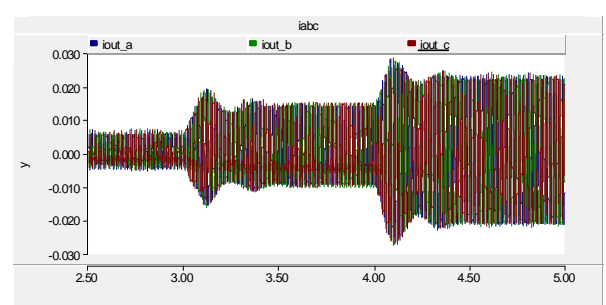

Fig.13 output current change of PV

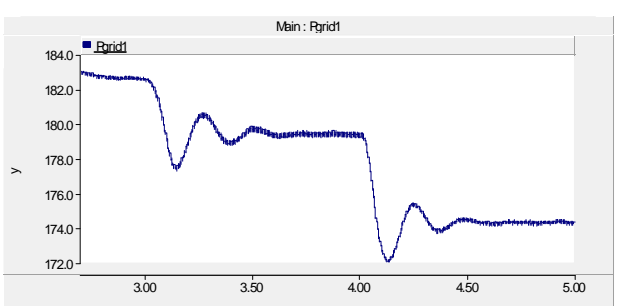

Fig. 14 power change of distribution network bus 1

\section{When the Wind Speed Changes}

The wind speed changes from $5 \mathrm{~m} / \mathrm{s}$ to $9 \mathrm{~m} / \mathrm{s}$ as shown in Figure 15 shows When the PV power generation system sunshine intensity $\mathrm{S}=1100 \mathrm{~W} / \mathrm{m}^{2}$ and the temperature $T=300 \mathrm{~K}$. Wind generation system output power changes as shown in Figure 16. Transient time of the wind speed changes of wind power generation system output longer than that of temperature or the intensity of sunshine changes by Fig. 6. The output current of the wind power system is shown in Figure 17, and the current has a small shock in the whole process of change. Distribution network bus 4 power changes as shown in Figure 18, distribution network output power reduce and the transient process is in a small shock with the increase of wind power generation system output

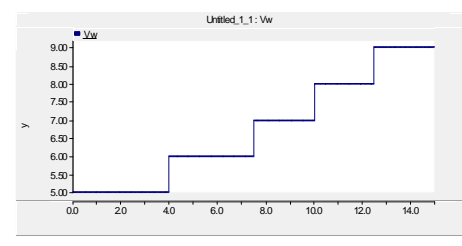

Fig. 15 wind speed of WT

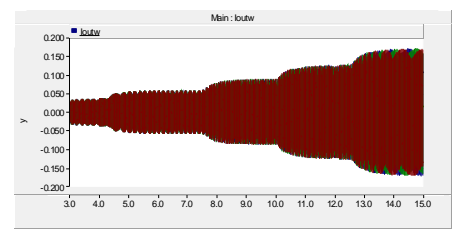

Fig. 17 output current change of WT

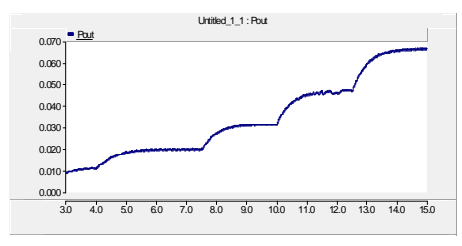

Fig. 16 output power change of WT

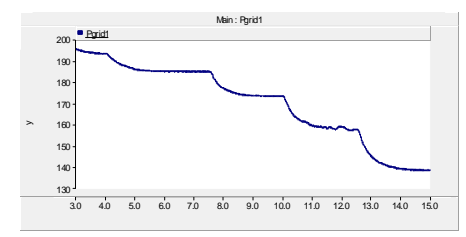

Fig. 18 power change of distribution network bus 1

\section{When Permeability Changes}

Intermittent DGs are usually considered as a special kind of load because of uncontrollability when the intermittent distributed power system is connected to the grid. the distribution network bus voltage change as shown in Figure 19 At the time of 2-4s the permeability was $24 \%$, at the time of 4-6s permeability was $59 \%$ and at the time of $6-8$ s permeability was $79 \%$.Voltage changes while permeability variation and the higher the permeability, higher the bus voltage. Voltage oscillation amplitude is smaller after reaching a steady and voltage transient time is long. Distribution network frequency changes as shown in Figure 20, from Figure 20, the greater the permeability, the greater the frequency of transient changes, until reaching $52 \mathrm{~Hz}$ and beyond the normal range of frequency. 


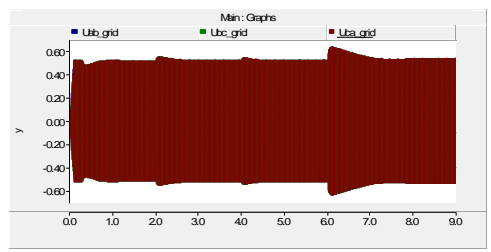

Fig. 19 voltage change of distribution network bus 1

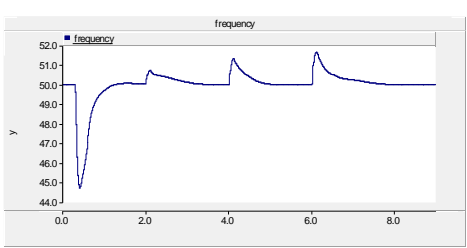

Fig. 20 frequency change of distribution network

\section{CONCLUSION}

The effects of PV systems and wind power generation system access distribution system transients, the changes of illumination intensity and temperature have different effects on network system, the changes of wind power generation system wind speed affect the fan output were studied in this paper. The inertia time constant of permanent magnet synchronous generator longer than that of PV power generation system, so transient changes of wind power system is longer than PV power generation system and distribution system transient time change is the same with wind power generation system. The voltage of the distribution network increases and the voltage response time become longer and the frequency is unstable with the increase supplying of the permeability of the distributed power.

\section{REFERENCES}

[1] WANG C. Modeling and control of hybrid wind/photovoltaic/fuel cell distribution generation systems[D]. Bozeman, USA: Montana State University, 2006.

[2] Li Wang, Ying-Hao Lin. Dynamic stability analyses of a photovoltaic array connected to a large utility grid[C]. Power Engineering Society Winter Meeting, Singapore, 2001: 476-480.

[3] Ryan C Campbell. A Circuit-based photovoltaic array model for power system studies[C]. Power Symposium NAPS 07 39th, North American, 2007:97-101.

[4] Lie Xu, Bjarne R Andersen, Philop Cartwright. VSC Transmission Operating Under Unbalanced AC Conditions-Analysis and Control Design[J]. IEEE Trans. On Power Delivery. 2005.

[5] Chen Y, Dinavahi V. Digital hardware emulation of universal machine and universal line models for real-time electromagnetic transient simulation[J]. IEEE Transactions on Industrial Electronics, 2012, 59(2): 1300-1309.

[6] Myaing A, Dinavahi V, FPGA-based real-time emulation of power electronic systems with detailed representation of device characteristics[J]. IEEE Transactions on Industrial Electronics, 2011, 58(1): 358-368.

[7] MARTINS V F, BORGES C L T. Active distribution network integrated planning incorporating distributed generation and load response uncertainty[J]. IEEE Trans on Power Systems, 2011, 26(4): 2164-2172. 